\title{
Energy and Exergy Based Performance Analysis of Westinghouse AP1000 Nuclear Power Plant
}

\author{
Robert Benjamin Eshun \\ Faculty of Engineering, Ghana Technology University College, Accra, Ghana
}

Email address:

reshun@gtuc.edu.gh

\section{To cite this article:}

Robert Benjamin Eshun. Energy and Exergy Based Performance Analysis of Westinghouse AP1000 Nuclear Power Plant. Advances in Applied Sciences. Vol. 4, No. 1, 2019, pp. 1-10. doi: 10.11648/j.aas.20190401.11

Received: February 15, 2019; Accepted: April 1, 2019; Published: April 22, 2019

\begin{abstract}
Energy and exergy analyses of the performance of the Westinghouse Advanced Passive 1000-MWe Nuclear Plant (AP1000) was conducted with the primary objectives to identify and quantify the operational locations having the largest energy and exergy losses under normal operating conditions. The energy and exergy losses in the reactor units were determined from formulations of the energy and exergy rate balances based on the Gouy-Stodola theorem. The performance of the overall AP1000 plant was estimated by component wise modeling and detailed break-up of energy and exergy losses in the various plant sections. Operating at maximum core power of $3400 \mathrm{MW}$, the AP1000 reactor core experienced moderately small thermal loss of $125.1 \mathrm{MW}$ and very substantial exergy consumption of $1814.8 \mathrm{MW}$ achieving energy and exergy efficiencies of $96.3 \%$ and $46.6 \%$ respectively. For the entire AP1000 plant, energy losses occurred mainly in the condenser where $1849.8 \mathrm{MW}$ was lost to the environment. Exergy analysis, however, revealed lost energy in the condenser was thermodynamically insignificant due to the low quality and that irreversible losses of $1868.4 \mathrm{MW}$ in the reactor and steam generator assembly were the major source of irreversibilities in the plant. The study confirmed that the major heat transfer inefficiencies occurring in nuclear reactor plants resided in the reactor cores and efforts to increase the efficiency of the plant should concentrate on the design of the core components.
\end{abstract}

Keywords: Energy Analysis, Exergy Analysis, Gouy-Stodola Theorem, Irreversibility, Maximum Work, Energy Conversion Systems, Reactor Core, Nuclear Power Plant

\section{Introduction}

The emphasis on energy resource conservation and environmentally sustainable power production processes have generated increased interest among researchers and in industry to find high efficiency and low emission solutions to energy related problems.

Conventionally, energy efficiency analyses emphasize reducing energy emissions or wastes to improve efficiency. The only inefficiencies detected by the analysis of a system are the energy transfers out of the system that are not further used in the installation $[1,2]$.

Consequently, energy analysis provides no information on the degradation of energy or resources during a process and does not account for the usefulness (or quality) of the various energy and material streams flowing through a system and exiting as products and wastes [3,4].

All real processes involve energy losses due to their irreversible nature. In real processes, energy is not destroyed but rather transformed into other forms less suitable for feeding and driving real processes. Hence beside energy, the concept of exergy was introduced to characterize the quality of the energy under consideration. The exergy method of analysis, based on the second law of thermodynamics and the concept of irreversible production of entropy, overcomes the limitations of energy analysis $[5,6]$.

Exergy is the maximum work potential of energy in relation to the environment and is a measure of the ability to do work by the variety of energy streams (mass, heat, and work) that are transferred through a system [7]. The key attribute of exergy is the provision of common grounds for the comparison of the various energy streams based on the second law of thermodynamics.

The elementary irreversible phenomena that generate entropy are mechanical or hydraulic friction, heat transfer with a finite temperature gradient, diffusion with a finite gradient of concentration, and the mixing of substances with different parameters and chemical composition [3]. 
The exergy method is useful for providing a detailed breakdown of the losses for plants and components, in terms of waste emissions and irreversible losses, and quantifies the types, causes and locations of the losses, such that inefficiencies in processes are better pinpointed. In exergy analysis, more meaningful efficiencies are evaluated since exergy efficiencies are always a measure of the approach to the physically ideal output [3].

In systems analysis, the irreversibilities associated with combustion, heat transfer, mixing and pressure losses are considered separately and used to estimate the contribution of each component or process to the total exergy destruction in a system [8].

There are various irreversible losses that exist within energy production systems which transform part of the total energy to forms unavailable for power production [9]. Thus complete energy analysis of thermal power and other energy intensive systems requires a combination of the first and second laws of thermodynamics to account for the quality and quantity of the energy flows [10].

The research problem investigated was to develop a mathematical model of the thermodynamic efficiency of the Westinghouse Advanced Passive 1000-MWe Nuclear Plant (AP100) through formulating of energy and exergy balances for the Westinghouse AP1000 power reactor system under steady state conditions in order to:

(1) Determine of the magnitude of energy losses and dissipations (or exergy consumptions) in the energy conversion processes within the components of the reactor assembly.
(2) Identify of the locations and types of irreversibilities within the systems, and

(3) specification of the sites or components that contribute significant losses to the system.

(4) Determine of the energy and exergy efficiency of the reactor components and the overall operating efficiencies under nominal conditions.

(5) Contribute to a comprehensive understanding of the thermodynamic characteristics of reactor systems.

\section{Method}

\subsection{Schematic Setup}

The general equations used in conventional energy and exergy analysis are shown in Table 1 . The schematic setup for the plant was obtained through sectioning the reactor core and process cycles separately and modelling the exergy and energy transfer processes of the individual components within the sectioned parts to perform the analysis

According to Dincer and Rosen, the energy and exergy transfer processes that occur within the steam generation of a water cooled nuclear reactor consists of heating of the fuel pellets to their maximum temperature, transfer of the heat within the fuel pellets to the surface of the pellets, transfer of heat from the surface of the fuel pellets to the cladding outer surface, and the transfer of heat from the cladding surface to the primary coolant [1]. The equations employed to calculate the exergy efficiencies of the reactor core are shown in Table 2.

Table 1. General equations used in conventional energy and exergy analysis [3].

\begin{tabular}{lll}
\hline & Equation & No. \\
\hline Energy Balance & $\frac{d E x_{c v}}{d t}=\sum_{j}\left(1-\frac{T_{o}}{T_{j}}\right) \dot{Q}_{j}-\left(\dot{W}_{c v}-p_{o} \frac{d V_{c v}}{d t}\right)+\sum_{i} \dot{m}_{i} x_{f i}-\sum_{e} \dot{m}_{e} x_{f e}-\dot{I}_{d}$ & 1 \\
Entropy Analysis & $\frac{d S_{c v}}{d t}=\sum_{j} \frac{\dot{Q}_{j}}{T_{j}}+\sum_{i} \dot{m}_{i} s_{i}-\sum_{e} \dot{m}_{e} s_{e}+\dot{S}_{g e n}$ & 2 \\
Irreversibility & $I=\dot{W}_{u, \text { max }}-\dot{W}_{\text {actual }}$ & 3 \\
Irreversibility & $I_{d}=T_{o} S_{g e n}$ & 4 \\
(Gouy-Stodola) & $\eta=\frac{\dot{W}_{c y c l e}}{\dot{Q}_{\text {in }}}=\frac{\dot{W}_{\text {actual }}}{\dot{Q}_{\text {in }}}$ & 5 \\
Energy efficiency & $\psi=\frac{\dot{W}_{a c t u a l}}{\dot{W}_{u, \text { max }}}$ & 6 \\
Exergy efficiency & $\eta_{R}=1-\frac{\dot{Q}_{\text {loss }}}{\dot{Q}_{\text {fission }}}$ & 7 \\
Energy efficiency of the reactor core & &
\end{tabular}

The experimental setup for the plant was obtained through sectioning the reactor core and process cycles separately and modelling the exergy and energy transfer processes of the individual components within the sectioned parts to perform the analysis.

According to Dincer and Rosen, the energy and exergy transfer processes that occur within the steam generation of a water cooled nuclear reactor consists of heating of the fuel pellets to their maximum temperature, transfer of the heat within the fuel pellets to the surface of the pellets, transfer of heat from the surface of the fuel pellets to the cladding outer surface, and the transfer of heat from the cladding surface to the primary coolant [1]. The equations employed to calculate the exergy efficiencies of the reactor core are shown in Table 2.

The process cycle for the AP1000 power cycle was idealized with the simplified model of Figure 1, which was derived from the complete heat balance of Figure 2 [11] based on the regenerative vapour cycle design which drives steam through a series of low and high pressure turbine generators, and preheating feed-water in connected low and high pressure heat exchangers and open de-aerating heat chambers. 
Table 2. Equations employed to calculate the exergy efficiencies of the reactor core [12].

\begin{tabular}{|c|c|c|c|}
\hline & Parameter & Equations & No. \\
\hline \multirow[t]{5}{*}{ The maximum work } & Fission & $\left(\dot{W}_{u, \max }\right)_{\text {fission }} \approx \dot{Q}_{\text {fission }}$ & 8 \\
\hline & Fuel rod centerline & $\left(\dot{W}_{u, \max }\right)_{f u e l}=\dot{Q}_{f i s s i o n}\left(1-\frac{T_{o}}{T_{\max }}\right)$ & 9 \\
\hline & Outer surface of pellet & $\left(\dot{W}_{u, \text { max }}\right)_{\text {pellet }}=\dot{Q}_{\text {fission }}\left(1-\frac{T_{o}}{T_{p}}\right)$ & 10 \\
\hline & Outer surface of clad & $\left(W_{u, \max }\right)_{\text {clad }}=\dot{Q}_{f i s s i o n}\left(1-\frac{T_{o}}{T_{c}}\right)$ & 11 \\
\hline & Coolant & $\left(\dot{W}_{u, \max }\right)_{\text {coolant }}=\dot{m}\left[\left(h_{e}-h_{i}\right)-T_{o}\left(s_{e}-s_{i}\right)\right]$ & 12 \\
\hline \multirow[t]{5}{*}{ Irreversibility } & Fuel rod & $\dot{I}_{\text {fuel }}=\left(\dot{W}_{u, \max }\right)_{\text {fission }}-\left(\dot{W}_{u, \max }\right)_{\text {fuel }}=\left(\dot{W}_{u, \max }\right)_{\text {fission }}\left(\frac{T_{o}}{T_{\max }}\right)$ & 13 \\
\hline & Pellet & $\dot{I}_{\text {pellet }}=\left(\dot{W}_{u, \max }\right)_{\text {fuel }}-\left(\dot{W}_{u, \max }\right)_{\text {pellet }}$ & 14 \\
\hline & Clad & $\dot{I}_{\text {clad }}=\left(\dot{W}_{u, \max }\right)_{\text {pellet }}-\left(\dot{W}_{u, \max }\right)_{\text {clad }}$ & 15 \\
\hline & Coolant & $\dot{I}_{\text {coolant }}=\left(\dot{W}_{u, \max }\right)_{\text {clad }}-\left(\dot{W}_{u, \max }\right)_{\text {coolant }}$ & 16 \\
\hline & Reactor (total) & $\dot{I}_{\text {reactor }}=\dot{I}_{\text {fission }}+\dot{I}_{\text {fuel }}+\dot{I}_{\text {pellet }}+\dot{I}_{\text {clad }}+\dot{I}_{\text {coolant }}$ & 17 \\
\hline Exergy efficiency & & $\psi_{R}=1-\frac{i_{\text {reactor }}}{\left(\dot{W}_{u, \max }\right)_{\text {ission }}}$ & 18 \\
\hline
\end{tabular}

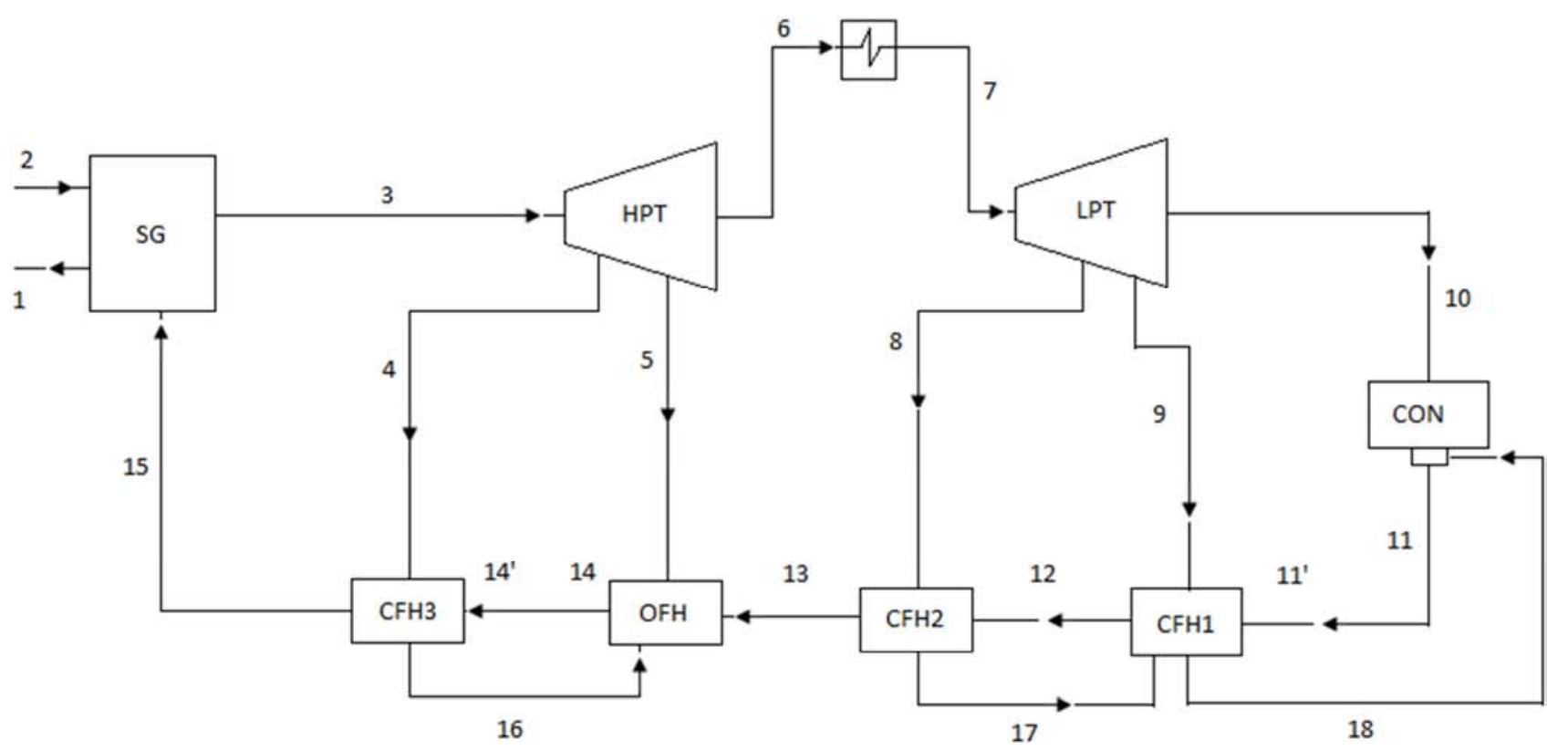

(a)

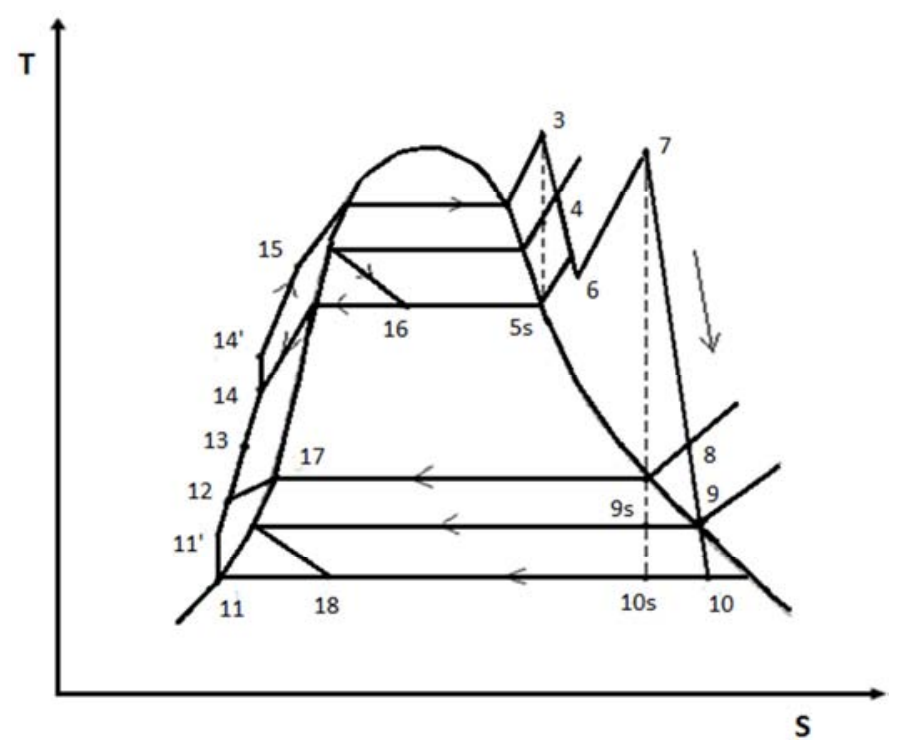

(b)

Figure 1. (a) Simplified model of the AP1000 process cycle (b) T-S diagram of the regenerative vapour cycle. The property data for the flow streams are listed in Table 4. 


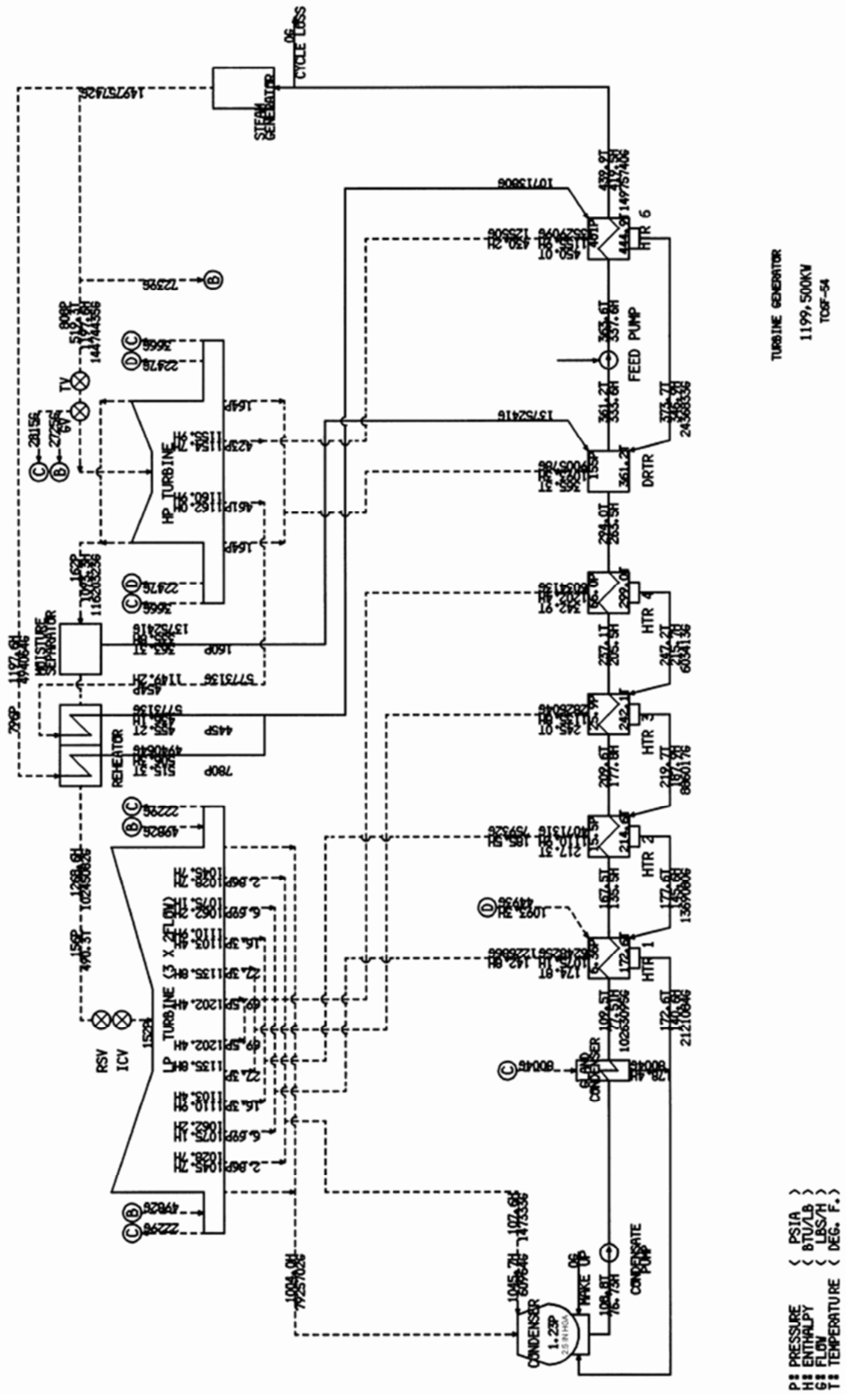

Figure 2. AP1000 steam and power conversion system with process data [8] drops. 


\subsection{Thermodynamic Analysis}

The thermodynamic modelling of the subsystems of the process cycle of the AP1000 plant was initiated by considering in turns the major components working under steady state.

Operating under full power conditions, the steady state fuel temperature distribution within the AP1000 reactor core was assumed to be maximum at the fuel centerline at $T_{\max }$ $\left(1339.9^{\circ} \mathrm{C}\right)$ and fall to temperature $T_{c}\left(315.75^{\circ} \mathrm{C}\right)$ at the fuel cladding surface [13].

General equations used to calculate the energy and exergy rates for the identified streams in the simulated AP1000 process cycle of Figure 1, and the general performance parameters used in the exergy analysis are presented in Table 3.

The process cycle was analysed based on the following assumptions and simplifications:

(1) Kinetic and potential energy changes were negligible for all processes.

(2) Pump work as a contribution to net work output was insignificant

(3) Frictional irreversibilities in the turbines were ignored (i.e. turbines had mechanical efficiencies of $100 \%$.)

(4) The reference environment model used had the following property values: temperature $T_{o}=32^{\circ} \mathrm{C}$ and pressure $P_{o}=1 \mathrm{~atm}$

(5) Turbine output $\left(\dot{W}_{T}\right)=1199.5 \mathrm{MW}$

Thus the only irreversibilities considered for all the plant components were internal irreversibilities due to heat transfer.

\subsection{Computation of Energy and Exergy Loss Rates}

General equations used to calculate the energy and exergy loss rates for streams and general performance parameters used in the conventional exergy analysis are given in Table 3.

The operational data used in the analysis of the processes within the AP1000 power cycle is presented in Table 5 [8]. The enthalpy and entropy values were obtained by finding the mass weighted average enthalpy and entropy values of streams specified for components in the AP1000 Design Control Document [11].

The energy and exergy rate balances for the AP1000 power cycle, presented in Table 3, was solved for the energy and exergy loss rates specified for the various plant components through the substitution of the parameters of mass flow rates, enthalpy and entropy values into the respective equations.

The total energy and exergy loss values were obtained from an aggregation of the energy and exergy loss values computed for the various plant components.

Table 3. Equations employed to calculate the energy and exergy loss rates of the plant components.

\begin{tabular}{|c|c|c|c|}
\hline & Parameter & Equations & No. \\
\hline \multirow[t]{7}{*}{ Energy } & Entire turbine & $\begin{array}{l}\dot{W}_{T}=\dot{m}_{3}\left(h_{3}-h_{4}\right)+\left(\dot{m}_{3}-\dot{m}_{4}\right)\left(h_{4}-h_{5}\right)+\left(\dot{m}_{3}-\dot{m}_{4}-\dot{m}_{5}\right)\left(h_{5}-h_{6}\right)+ \\
\dot{m}_{7}\left(h_{7}-h_{8}\right)+\left(\dot{m}_{7}-\dot{m}_{8}\right)\left(h_{8}-h_{9}\right)+\left(\dot{m}_{7}-\dot{m}_{8}-\dot{m}_{9}\right)\left(h_{9}-h_{10}\right)-\text { Energy loss }\end{array}$ & 19 \\
\hline & Steam generator & Energy loss $(\mathrm{SG})=\dot{m}_{1}\left(h_{2}-h_{1}\right)-\dot{m}_{3}\left(h_{15}-h_{3}\right)$ & 20 \\
\hline & Closed Feedwater Heater No. 1 & Energy loss (CFH1) $=\dot{m}_{9} h_{9}+\dot{m}_{17} h_{17}-\dot{m}_{11}\left(h_{12}-h_{11}\right)-\dot{m}_{18} h_{18}$ & 21 \\
\hline & Closed Feedwater Heater No. 1 & Energy loss $(\mathrm{CFH} 2)=\dot{m}_{8}\left(h_{8}-h_{17}\right)-\dot{m}_{12}\left(h_{13}-h_{12}\right)$ & 22 \\
\hline & Open feedwater heater & Energy loss $(\mathrm{OFH})=\dot{m}_{5} h_{5}+\dot{m}_{16} h_{16}+\dot{m}_{13} h_{13}-\dot{m}_{14} h_{14}$ & 23 \\
\hline & Closed Feedwater Heater No. 1 & Energy loss $(\mathrm{CFH} 3)=\dot{m}_{4}\left(h_{4}-h_{16}\right)-\dot{m}_{14}\left(h_{15}-h_{14}\right)$ & 24 \\
\hline & Condenser & Energy loss $($ Con $)=\dot{m}_{10}\left(h_{10}-h_{11}\right)-\dot{m}_{c w}\left(h_{c o}-h_{c i}\right)$ & 25 \\
\hline \multirow[t]{8}{*}{ Exergy Balance } & High pressure turbine & $T_{o} \dot{S}_{g e n}=T_{o}\left[\dot{m}_{3}\left(s_{4}-s_{3}\right)+\left(\dot{m}_{3}-\dot{m}_{4}\right)\left(s_{5}-s_{4}\right)+\left(\dot{m}_{3}-\dot{m}_{4}-\dot{m}_{5}\right)\left(s_{6}-s_{5}\right)\right]$ & 26 \\
\hline & Low pressure turbine & $T_{o} \dot{S}_{g e n}=T_{o}\left[\dot{m}_{7}\left(s_{8}-s_{7}\right)+\left(\dot{m}_{7}-\dot{m}_{8}\right)\left(s_{9}-s_{8}\right)+\left(\dot{m}_{7}-\dot{m}_{8}-\dot{m}_{9}\right)\left(s_{10}-s_{9}\right)\right.$ & 27 \\
\hline & steam generator (Irreversibility & $T_{o} \dot{S}_{g e n}=T_{o}\left[\dot{m}_{1}\left(s_{1}-s_{2}\right)-\dot{m}_{3}\left(s_{15}-s_{3}\right)\right]$ & 28 \\
\hline & Closed Feedwater Heater No.1 & $T_{o} \dot{S}_{g e n}=T_{o}\left[\dot{m}_{18} s_{18}+\dot{m}_{11^{\prime}}\left(s_{12}-s_{11^{\prime}}\right)-\dot{m}_{9} s_{9}-\dot{m}_{17} s_{17}\right]$ & 29 \\
\hline & Closed Feedwater Heater No.2 & $T_{o} \dot{S}_{g e n}=\left[\dot{m}_{8}\left(h_{8}-h_{17}\right)-\dot{m}_{12}\left(h_{13}-h_{12}\right)\right]-T_{o}\left[\dot{m}_{8}\left(s_{8}-s_{17}\right)-\dot{m}_{12}\left(s_{13}-s_{12}\right)\right]$ & 30 \\
\hline & Open Feedwater Heater & $T_{o} \dot{S}_{g e n}=T_{o}\left[\dot{m}_{14} s_{14}-\dot{m}_{5} s_{5}-\dot{m}_{16} s_{16}-\dot{m}_{13} s_{13}\right]$ & 31 \\
\hline & Closed Feedwater Heater No.3 & $T_{o} \dot{S}_{g e n}=\left[\dot{m}_{4}\left(h_{4}-h_{16}\right)-\dot{m}_{14}\left(h_{15}-h_{14}\right)\right]-T_{o}\left[\dot{m}_{4}\left(s_{4}-s_{16}\right)-\dot{m}_{14}\left(s_{15}-s_{14}\right)\right]$ & 32 \\
\hline & Condenser & $T_{o} \dot{S}_{g e n}=T_{o}\left[m_{10}\left(s_{10}-s_{11}\right)-\dot{m}_{c w}\left(s_{c o}-s_{c i}\right)\right]$ & 33 \\
\hline Energy efficiency & Plant & $\eta_{\text {plant }}=\frac{\dot{W}_{\text {net }}}{\dot{E}_{\text {fuel }}}=\frac{\dot{W}_{T}}{\dot{Q}_{\text {fission }}}$ & 34 \\
\hline Exergy efficiency & Plant & $\psi_{\text {plant }}=\frac{\dot{W}_{\text {net }}}{E_{\text {fuel }}}=\frac{\dot{W}_{T}}{\dot{Q}_{\text {fission }}}$ & 35 \\
\hline
\end{tabular}

Table 4. Thermodynamic property data for flow streams listed in Figure 1(a).

\begin{tabular}{llllllll}
\hline State & $\begin{array}{l}\text { Mass flow rate } \\
\mathbf{k g} / \mathbf{s}\end{array}$ & $\begin{array}{l}\text { Enthalpy }^{1} \\
\mathbf{k J} / \mathbf{k g}\end{array}$ & $\begin{array}{l}\text { Entropy }^{\mathbf{1}} \\
\mathbf{k J} / \mathbf{k g} . \mathbf{K}\end{array}$ & $\begin{array}{l}\text { Temp } \\
{ }^{\circ} \mathbf{C}\end{array}$ & $\begin{array}{l}\text { Pressure } \\
\mathbf{M P a}\end{array}$ & Condition & Vapour fraction \\
\hline 0 & & & & 32.0 & 0.101 & & \\
1 & $14275.8^{1}$ & 1239.5 & 3.073 & 280.7 & 15.513 & Subcooled liquid & 0.0 \\
2 & $14275.8^{1}$ & 1468.9 & 3.503 & 321.1 & 15.513 & Subcooled liquid & 0.0 \\
3 & 1886.7 & 2765.8 & 5.924 & 270.7 & 5.571 & Saturated vapour & 1.0 \\
4 & 170.4 & 2688.6 & 7.257 & 232.2 & 2.916 & Two phase mixture & 0.56 \\
5 & 113.4 & 2543.0 & 5.840 & 229.4 & 1.103 & Two phase mixture & 0.40 \\
\hline
\end{tabular}




\begin{tabular}{|c|c|c|c|c|c|c|c|}
\hline State & $\begin{array}{l}\text { Mass flow rate } \\
\mathrm{kg} / \mathrm{s}\end{array}$ & $\begin{array}{l}\text { Enthalpy }^{1} \\
\mathrm{~kJ} / \mathrm{kg}\end{array}$ & $\begin{array}{l}\text { Entropy }^{1} \\
\text { kJ/kg. K }\end{array}$ & $\begin{array}{l}\text { Temp } \\
{ }^{\circ} \mathrm{C} \\
\end{array}$ & $\begin{array}{l}\text { Pressure } \\
\mathrm{MPa}\end{array}$ & Condition & Vapour fraction \\
\hline 6 & 1464.1 & 2543.0 & 5.840 & 184.1 & 1.117 & Two phase mixture & 0.90 \\
\hline 7 & 1290.9 & 2950.8 & 7.980 & 254.6 & 1.075 & Saturated vapour & 1.0 \\
\hline 8 & 172.5 & 2695.4 & 6.901 & 152.3 & 0.191 & Saturated vapour & 1.0 \\
\hline 9 & 94.8 & 2146.0 & 7.830 & 79.3 & 0.046 & Two phase mixture & 0.84 \\
\hline 10 & 1025.9 & 2252.0 & 8.407 & 42.7 & 0.008 & Two phase mixture & 0.98 \\
\hline 11 & 1293.1 & 178.4 & 0.606 & 42.7 & 0.008 & Saturated liquid & 0.0 \\
\hline $11^{\prime}$ & 1293.1 & 180.7 & 0.570 & 43.1 & 0.043 & Subcooled liquid & 0.0 \\
\hline 12 & 1293.1 & 315.2 & 1.070 & 95.7 & 0.247 & Subcooled liquid & 0.0 \\
\hline 13 & 1293.1 & 612.9 & 1.795 & 145.6 & 1.068 & Subcooled liquid & 0.0 \\
\hline 14 & 1886.7 & 776.0 & 2.166 & 182.9 & 1.068 & Subcooled liquid & 0.0 \\
\hline $14^{\prime}$ & 1886.7 & 785.3 & 2.187 & 184.2 & 2.764 & Subcooled liquid & 0.0 \\
\hline 15 & 1886.7 & 975.8 & 2.578 & 226.6 & 5.570 & Subcooled liquid & 0.0 \\
\hline 16 & 306.9 & 806.9 & 2.900 & 189.8 & 1.068 & Subcooled liquid & 0.0 \\
\hline 17 & 172.5 & 338.7 & 1.080 & 80.9 & 1.190 & Subcooled liquid & 0.0 \\
\hline 18 & 267.2 & 327.0 & 1.081 & 78.1 & 0.043 & Subcooled liquid & 0.0 \\
\hline Cwin & 37665.8 & 137.0 & 0.453 & 32.0 & 0.101 & Subcooled liquid & 0.0 \\
\hline Cwout & 37665.8 & 185.0 & 0.663 & 46.8 & 0.101 & Subcooled liquid & 0.0 \\
\hline
\end{tabular}

${ }^{1}$ The mass flow rate for the primary coolant was derived from the best estimate core flow provided in AP1000 Design Control Document [14].

\section{Results}

The results of the energy and exergy analysis of the AP1000 reactor core and process cycle are summarized in Table 5.

The results show that energy loss was largest in the condensation section, From first law analysis, a large quantity of energy (1808 MW) entered the condenser of which close to $100 \%$ was rejected to the environment. On the other hand, the power production section of the AP1000 unit (consisting of the turbines), experienced low combined energy loss of 17.6 MW. The preheating sections consisting of two low pressure closed heat exchangers, a high pressure closed heat exchanger and a deaerating chamber, were are found to have higher aggregate energy loss of $31.2 \mathrm{MW}$.

This was followed by the steam generation sections, consisting of the reactor core and steam generator devices. In this section, the energy loss was found to be moderate at 227.4MW with the reactor core contributing $125.1 \mathrm{MW}$ of the total, and the steam generator device experiencing the remaining 102.3MW loss.

The exergy analysis of components revealed that, the condenser consumed the least amount of exergy (28.4MW) during heat transfer to the cooling water. In the power production section of the AP1000 unit, the total exergy losses were found to be moderate at $99.3 \mathrm{MW}$. Of this total, the low pressure turbine was observed to account for the highest loss of 72.4 MW, with the high pressure turbine contributing a loss of 26.9 MW.

The preheating sections were found to have small exergy consumptions adding up to a total loss of 33.6MW. The exergy consumption associated with the reactor core and steam generator assembly, collectively called the steam generation sections, was found to be substantial contributing $1868.4 \mathrm{MW}$ of exergy loss, thereby accounting for $92 \%$ of the total exergy consumed.

The main energy process in the steam generation sections was heat transfer, and of the total exergy consumed, $1814.8 \mathrm{MW}$ was consumed in the heat transfer processes of the reactor core, and 53.6MW internally consumed in the steam generator device.

The overall energy and exergy efficiency values were calculated using $\dot{W}_{T}=1199.5 \mathrm{MW}$ and modeled as the theoretical energy and exergy efficiency values. These were found to be $35.3 \%$. Consequently, the theoretical energy and exergy loss values calculated from were found to be same at $2200.5 \mathrm{MW}$

\section{Discussion}

The energy analysis of the AP1000 reactor core indicated that operating at nominal core power of $3400 \mathrm{MW}$, energy was lost at the rate of $125.1 \mathrm{MW}$ to the surroundings, and transferred at the rate of 3274.9 MW to the primary coolant. On percent basis, only $3.7 \%$ of the total heat (energy) generated from the fuel was wasted, yielding a reactor energy efficiency of $96.3 \%$.

The exergy consumption in the AP1000 reactor core was separated into irreversible losses in heating the fuel centerline to the maximum temperature of $1339.9^{\circ} \mathrm{C}$, transferring of heat to the cladding surface at $315.75^{\circ} \mathrm{C}$, and heating of the primary coolant.

Of the 1814.8 MW total exergy consumption observed in the reactor core, 643.2 MW was consumed in heating the fuel centerline to the maximum temperature, 1118.6 MW in transferring heat to the cladding surface, and 53.1 MW was destroyed in heating the primary coolant. The maximum work available from the coolant was observed to be 1585.2 MW, thereby achieving exergy efficiency of $46.6 \%$. 
Table 5. Energy and exergy loss rates in sections of AP1000 power cycle.

\begin{tabular}{|c|c|c|c|c|}
\hline \multirow{2}{*}{ Section/device } & \multicolumn{2}{|c|}{ Energy loss rate } & \multicolumn{2}{|c|}{ Exergy loss rate } \\
\hline & (MW) & $\%$ of total energy loss & (MW) & $\%$ of total exergy loss \\
\hline \multicolumn{5}{|l|}{ Steam generation section } \\
\hline \multicolumn{5}{|l|}{ Reactor } \\
\hline Fuel Centerline & - & & 643.2 & 31.7 \\
\hline Cladding surface & - & & 1118.6 & 55.1 \\
\hline Coolant & - & & 53.1 & 2.6 \\
\hline Total & 125.1 & 6.0 & 1814.8 & 89.4 \\
\hline Steam generator & 102.3 & 4.9 & 53.6 & 2.6 \\
\hline Section Total & 227.4 & 10.9 & 1868.4 & 92.0 \\
\hline \multicolumn{5}{|l|}{ Power production section } \\
\hline High-pressure turbine & - & & 26.9 & 1.3 \\
\hline Low-pressure turbine & - & & 72.4 & 3.6 \\
\hline Total & 17.6 & 0.8 & 99.3 & 4.9 \\
\hline \multicolumn{5}{|l|}{ Condensation section } \\
\hline Condenser((rejected) & 1808.0 & & 28.5 & \\
\hline Total & 1808.0 & 86.7 & 28.5 & 1.4 \\
\hline \multicolumn{5}{|l|}{ Preheat section } \\
\hline Low-pressure heat exchanger (CFH1) & 0.6 & 0.0 & 2.0 & 0.1 \\
\hline Low-pressure heat exchanger (CFH2) & 21.5 & 1.0 & 1.2 & 0.1 \\
\hline Deaerating heat exchanger (OFH) & 7.9 & 0.4 & 10.9 & 0.5 \\
\hline High-pressure heat exchanger (CFH3) & 1.2 & 0.1 & 19.5 & 1.0 \\
\hline Total & 31.2 & 1.5 & 33.6 & 1.7 \\
\hline General Total & 2084.2 & 100.0 & 2029.8 & 100.0 \\
\hline
\end{tabular}

The high thermal efficiency and moderate exergy efficiency achieved by the AP1000 reactor core was ascribed to the high temperatures of heat generation in the fuel, and heat-transfer under high temperature and pressure to the coolant. By this mechanism, the primary circuit maintained a high average temperature of heat addition to the working fluid in the secondary circuit.

The exergy destruction profile of the AP1000 reactor, which detailed the sectional contributions to total consumption within the core, showed that a substantial proportion $(97 \%)$ of total exergy consumption in the core was associated with heat transfer processes occurring within the fuel meat. This finding was consistent with the exergy consumption profile observed for the nuclear reactor of the Pickering Nuclear Generating Station in Canada [1].

For the AP1000 power cycle, the theoretical values of the plant overall energy and exergy efficiencies were found to be similar. However, the energy and exergy analysis revealed that individual component contributions to the total energy and exergy losses differed significantly for most plant sections as depicted in Figures 3 \& 4.

\section{Comparison Chart}

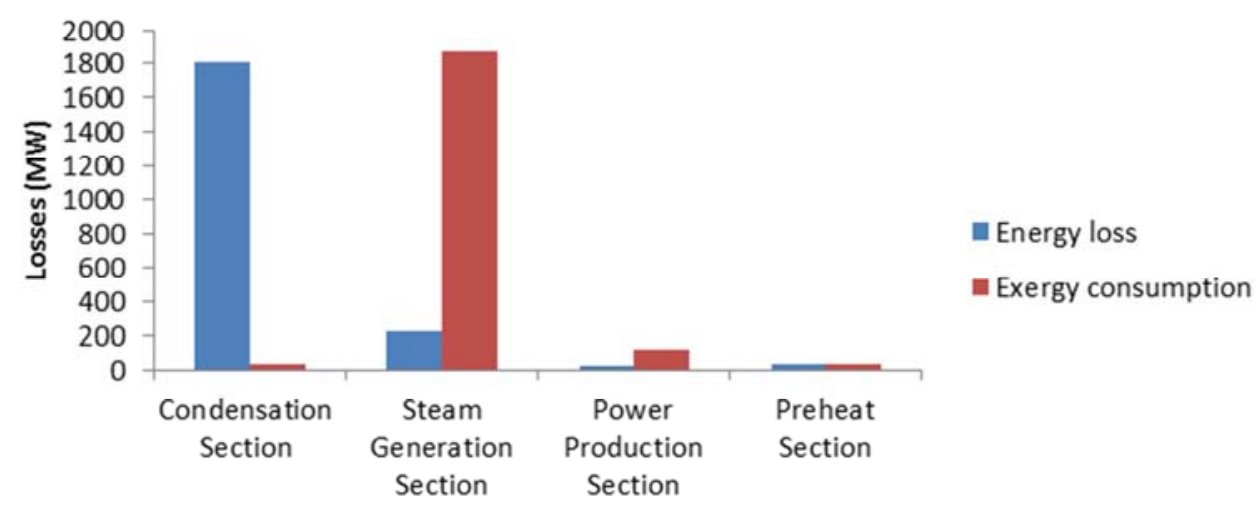

Figure 3. Comparison of sectional energy and exergy losses within the AP1000 plant. 

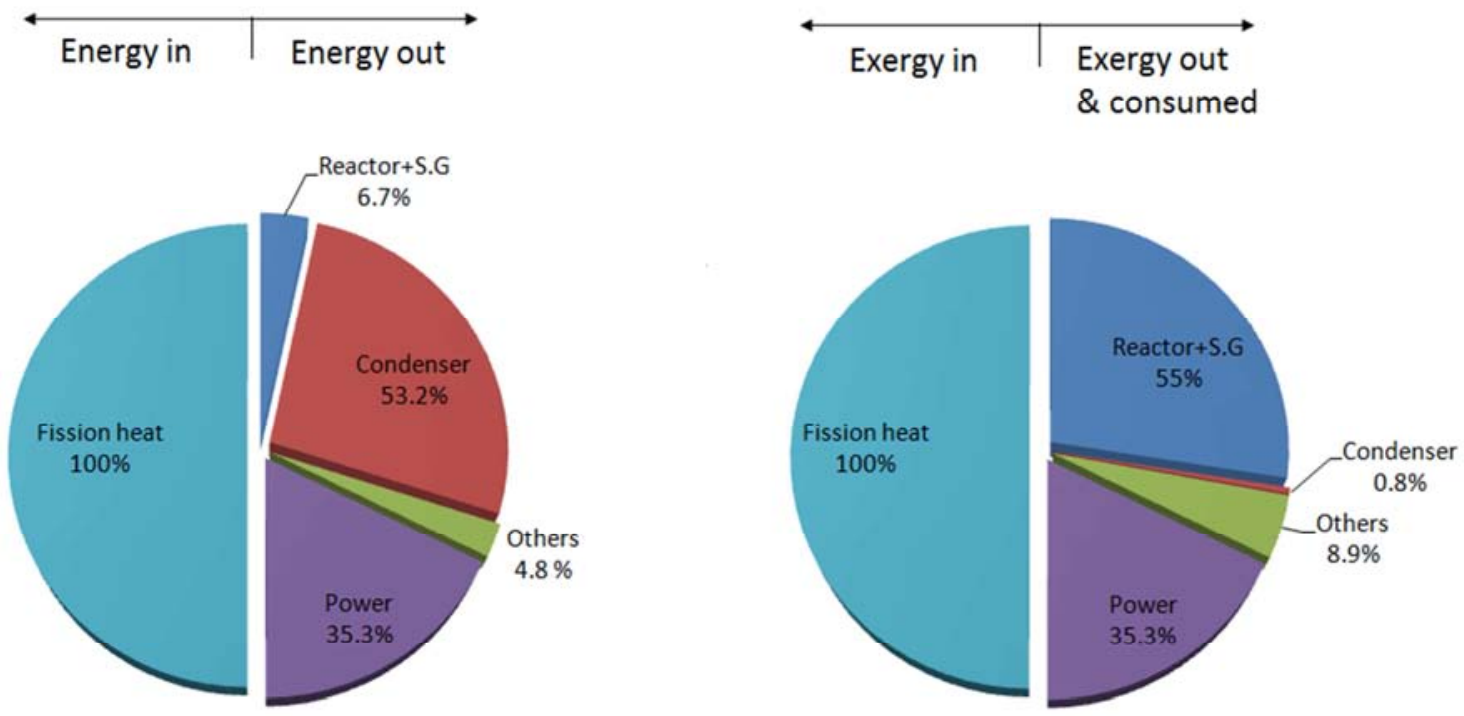

Figure 4. Energy and exergy balances for the entire AP1000 plant indicating power input, output and sectional losses.

Energy analysis, thus, leads to the erroneous conclusion that almost all losses in net work output were associated with heat rejected by the condensers. However, as reported by Dincer [1], the sources for majority of useful losses were the steam generation sections which experienced the largest irreversible losses or internal consumptions.

The steam generation sections of the AP1000 unit appeared significantly more efficient on an energy basis than on an exergy basis. The implication was that although a large quantity of the input energy was transferred to the coolant, and subsequently to the working fluid, the quality of energy was degraded as it was transferred.

The overall energy efficiency value calculated for the AP1000 plant was observed to be comparable to the value specified from literature [15]. The marginal deviation was ascribed to the assumptions, simplifications and idealizations adopted for the study.

Generally, the energy loss and exergy consumption values obtained for the AP1000 plant were found to be in broad agreement with other published works on nuclear power plants, and indicated the operational locations with the biggest potential for efficiency improvements as reported by the researchers $[1,16]$.

\section{Conclusion}

In the study, energy and exergy analysis of the Westinghouse Advanced Passive 1000-MWe Nuclear Plant (AP1000) was presented. The primary objectives of the study were to analyze the AP1000 reactor core and power cycle separately, and to identify and quantify the sites having the largest energy and exergy losses under normal operating conditions.

Mathematical models of the energy and exergyrate balances for the AP1000 plant were formulated under steady state normal operating conditions and evaluated using process data sourced from literature and AP1000 design documents.

Of the $3400 \mathrm{MW}$ core power generated by the AP1000, heat was lost at the rate of $125.1 \mathrm{MW}$ to the environment, and transferred at a rate of $3274.9 \mathrm{MW}$ to the reactor coolant, yielding a thermal efficiency of $26.7 \%$. Exergy analysis, on the other hand, revealed that of the total exergy (3400 MW) input to the reactor, $1814.8 \mathrm{MW}$ was consumed in the reactor core.

The AP1000 reactor core achieved very high energy efficiency and modest exergy efficiency which was comparable to other power reactor cores. This was attributed to the high temperatures associated with heat generation in the fuel and heat-transfer to the coolant.

For the AP1000 plant, maximum energy loss was observed in the condenser where close to $100 \%$ of energy entering this section was rejected. The condenser alone accounted for $86.7 \%$ of the total energy loss by the power cycle to the environment. The overall energy efficiency of the plant based on fission power generated wasfound to be $35.3 \%$.

Exergy analysis of the AP1000 station showed that energy loss in the condenser was thermodynamically insignificant due to the low quality of the ejected heat. In terms of exergy consumption (or irreversible losses), substantial loss was found in the steam generation sections where 1868.4MW of exergy, constituting $55 \%$ of the fission exergy input, was destroyed.

The overall energy and exergy efficiency for the power cycle was found to be the same at $35.3 \%$. However, energy and exergy analyses gave markedly different accounts of the component contributions to the total losses in the plant. Thus, while energy analysis gave only the energy emissions from processes without providing information about internal losses, exergy analysis highlighted the degradations in energy quality as it was transferred.

Generally, the energy and exergy loss and efficiency values evaluated for the process subsections and overall plant were found to be comparable to modern power plants and 
were in broad agreement with other published works on nuclear power reactors.

The study demonstrated that nuclear reactor cores have the largest potential for efficiency improvement in nuclear plants and, therefore, efforts to increase station efficiency should concentrate on this section.

\section{Nomenclature}

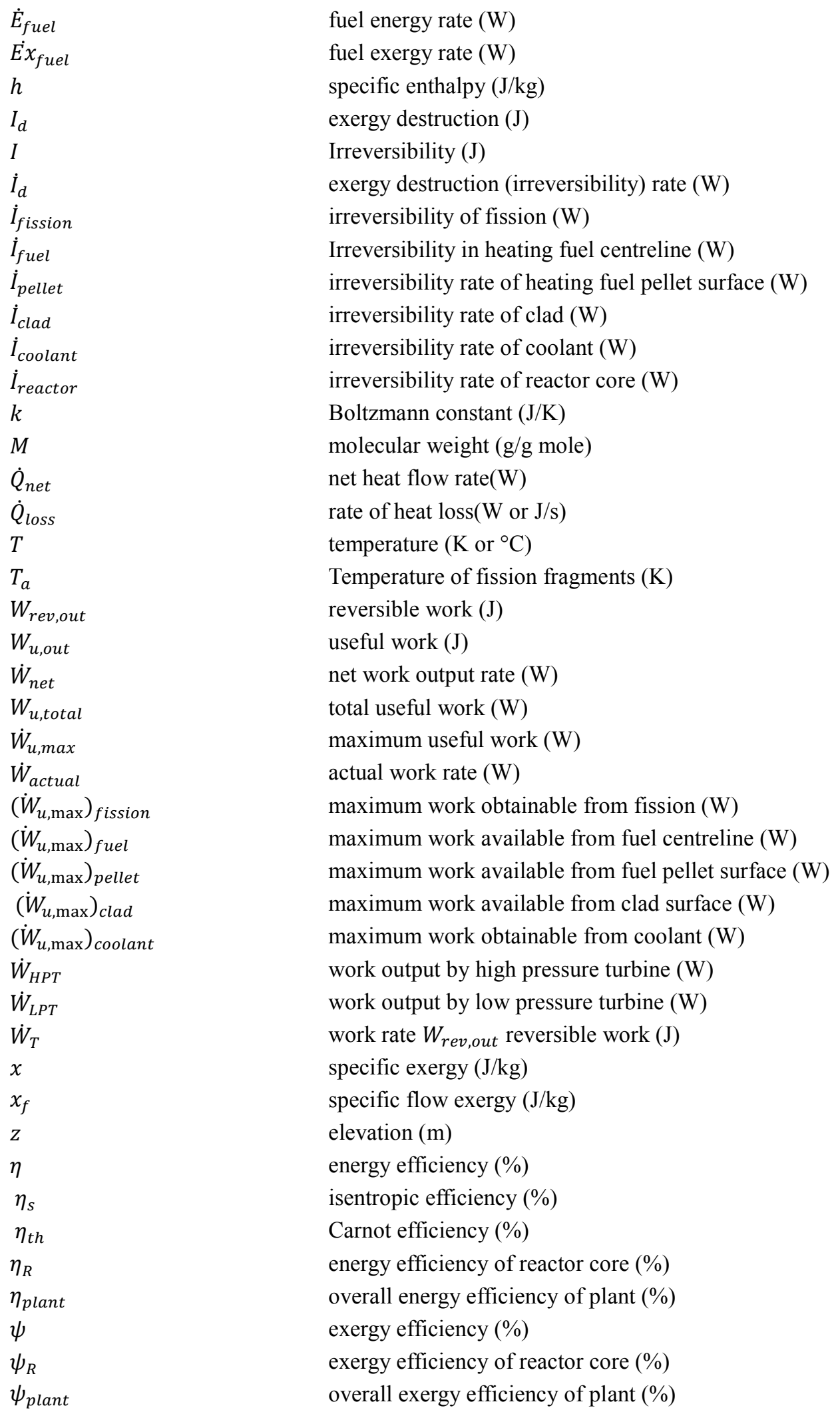




\section{References}

[1] Dincer I. and Rosen M. A., (2007), Exergy: energy, environment and sustainable development. Elsevier B. V., Amsterdam, Netherlands.

[2] Tsatsaronis G. and Cziesla F., (2009), Exergy and Thermodynamic Analysis. In Exergy, Energy System Analysis and Optimization (Frangopoulos, C. A., ed.), Vol. 1, EOLSS Publishers, Oxford, UK.

[3] Terzi R., (2018), Application of Exergy Analysis to Energy Systems, IntechOpen, doi.org/10.5772/intechopen.74433.

[4] Evola G., Costanzo V., and Marletta L., (2018), Exergy Analysis of Energy Systems in Buildings, Buildings, 8, 180; doi:10.3390/buildings 8120180

[5] Gilbert A. and Mesmer B., (2016), Uses of Exergy in Systems Engineering, In Proc. 2016 Conference on Systems Engineering Research, Mar 22- 24, Huntsville, Alabama, USA.

[6] Szargut J., (2005), Exergy Analysis, The Magazine of the Polish Academy of Sciences, Vol. 7, No. 3, Warsaw, Poland.

[7] Wall G. and Gong M., (2001), On Exergy and Sustainable Development - Part 1: Conditions and Concepts, Exergy, An International Journal, Vol, 1, No. 3, pp. 128 - 145.

[8] Tsatsaronis G. and Cziesla F., (2009), Exergy Analysis of Simple Processes, In Exergy, Energy System Analysis and
Optimization (Frangopoulos, C. A., ed.), Vol. 1, EOLSS Publishers, Oxford, UK.

[9] Lahey R. T. Jr. and Moody F J., (1993), The ThermalHydraulics of a Boiling Water Nuclear Reactor, $2^{\text {nd }}$ Edition, American Nuclear Society, Illinois, USA.

[10] Nikulshin V., Wu C. and Nikulshina V., (2002), Exergy efficiency calculation of energy intensive systems, Exergy, An International Journal, Vol. 2, pp. 78-86.

[11] Westinghouse Electric Co. LLC., (2002), AP1000 Design Control Document - Chapter 10: Steam and power conversion, Tier-2 material 10.1 .

[12] Todreas N. E. and Kazimi M. S., (1990), Nuclear Systems 1: Thermal Hydraulic Fundamentals, Taylor \& Francis, USA.

[13] Ameh L., (2012), Numerical Modelling of the Transient Temperature Distribution Within the Fuel Pin of the AP1000 Reactor During a Small Break Loss-of-Coolant Accident, MPhil Thesis, University of Ghana, Legon.

[14] Westinghouse Electric Co. LLC., (2002), AP1000 Design Control Document - Chapter 5: Reactor coolant system and connected systems, Tier-2 material 5.1, Revision 15.

[15] Westinghouse Electric Co. LLC. (2003), The Westinghouse AP1000 Advanced Nuclear Plant - Plant Description, Nuclear Engineering and Design, Vol. 236, pp. 1547-1557.

[16] Ahmet Durmayaz and HasbiYavuz, (2001), Exergy analysis of a pressurized-water reactor nuclear-power plant, Applied energy, Vol. 69, issue 1, pp. 39-57. 